\title{
Application of Lab-Scale MBBR to Treat Industrial Wastewater using K3 Carriers: Effects of HRT, High COD Influent, and Temperature
}

\author{
Ahmadlouydarab Majid* and Mehrazaran Mahna \\ Faculty of Chemical \& Petroleum Engineering, University of Tabriz, Iran
}

Submission: April 22, 2019; Published: June 28, 2019

*Corresponding author: Ahmadlouydarab Majid, Faculty of Chemical \& Petroleum Engineering, University of Tabriz, Iran, Po Box: 51666-16471

\begin{abstract}
In current study, the efficiency of a lab-scale MBBR was studied using K3 Kaldnes carriers. COD containing contaminant of 1000 to $3500 \mathrm{mg} / \mathrm{l}$ was used to examine the system performance by measuring BOD and COD at different HRTs, temperature and inlet CODs. It should be noted that K3 Kaldnes carriers was not used in previous studies. To determine optimal HRT, BOD and COD of the effluent were examined at different HRTs of 3, 5, 8, and 12 hours. The optimum HRT was 8 hours with COD removal efficiency more than $80 \%$. Despite of HRT=12 hours with the highest COD removal efficiency $\sim 86 \%, \mathrm{HRT}=8$ hours were chosen as the optimal HRT due to the time-consuming refinement process with only a slight difference of $3 \%$ in removal efficiencies. Additionally, the effects of temperature in the range of 19 to $32^{\circ} \mathrm{C}$ were studied at optimal HRT. The results indicate that there is a sharp change in COD removal efficiency slope at a temperature range between 20 to $25^{\circ} \mathrm{C}$ due to the high activity of microorganisms, leading to an increase in the COD removal efficiency from $70 \%$ to $~ 90 \%$. By increasing the temperature beyond $25^{\circ} \mathrm{C}$, the rate of increase in COD removal efficiency is reduced by as much as $94 \%$. According to the results, $27^{\circ} \mathrm{C}$ may be considered as the optimum temperature. Studying the effects of different inlet CODs up to $3500 \mathrm{mg} / \mathrm{l}$ reflects a non-monotonic behavior in MBBR's performance. In general, for all inlet CODs, MBBR system shows more than $80 \%$ removal efficiency.
\end{abstract}

Keywords: K3 carriers; MBBR; Wastewater; Lab-scale; High COD; MLSS

Abbreviations: ACC: Activated Carbon Concentration; MFR: Media Filling Ratio; TPH: Total Petroleum Hydrocarbon; TSS: Total Suspended Solid; BOD: Biological Oxygen Demand; COD: Chemical Oxygen Demand; ASP: Activated Sludge Process; MBR: Membrane Bioreactor System

\section{Introduction}

With industrial development in most countries, industrial wastewater effluents are also increasing. On the other hand, nowadays, the problem of water scarcity of the world has become one of the major concerns of the societies. Therefore, it is important to find an optimal and cost-effective way to recycle wastewater effluents. Industrial wastewater is made by water consumption in industrial activities and during various stages of production. Sometimes, they constitute the most dangerous type of wastewater. The bulk of industrial wastewater also contains contaminants that are characterized by organic matter (soluble or insoluble) which are the most important contaminates. The most important compounds of industrial wastewater are arsenic, cadmium, mercury, and lead. If they are not properly collected and routed to the wastewater treatment plant, these materials will enter flowing water streams and so to the environment, which will have irreversible harmness to the environment and human beings. The quantity and quality of wastewaters or industrial effluents in different factories and industries vary depending on the type of production, which lead to have variable treatment processes.
In the treatment of domestic and industrial wastewaters, physical and biological treatment methods are used to obtain environmental certification. The most important issue in the treatment of industrial wastewater is to understand its nature and the quality of elements and factors such as toxic compounds, decomposing factors, Total suspended solid (TSS), (biological oxygen demand) BOD, (chemical oxygen demand) COD and color. With solid knowledge about these factors, it will be possible to design appropriate treatment methods for industrial wastewater and effluents.

Among the available techniques, scavenging, flotation with soluble air, adsorption, and membrane filtration are physical methods. Also, chemical methods include chemical oxidation, electrochemical oxidation, and coagulation. However, physical and chemical methods are expensive because of the high cost of chemicals, equipment, and the need to remove excess sludge. Therefore, biological methods are preferred due to simplicity, affordability and environmental compatibility [1].

The biological methods involve two types of aerobic and anaerobic systems. Different biological aerobic systems for 
wastewater treatment such as activated sludge process (ASP), membrane filtration system (MBR), (up flow anaerobic sludge bioreactor) UASB system are utilized. However, all these systems have drawbacks that cannot be ignored [2]. In the activated sludge process (which is currently one of the most widely used methods for industrial wastewater treatment), there should be sludge returning cycle, which is costly. In addition, the removal efficiency of organic matters from wastewater is not satisfactory due to the complexity of chemicals in the wastewater industrial. Moreover, activated sludge system is continuously exposed to changes in $\mathrm{pH}$, temperature, solids concentration, erosion, and other parameters. Overall, these parameters decrease the system's life and efficiency [3]. Compared to the membrane bioreactor system (MBR) with the same apparent volume, (moving bed biofilm reactor) MBBR provides more specific volume (high capacity) for biological treatment. In MBR systems, membranes should also be cleaned regularly, which results in waste of time. The rest of the systems are not recommended due to the costs and low efficiency over long periods. Indeed, these are two main factors of being a non-optimal system. Thus, MBBR can be considered as an innovative and cost-effective with high removal efficiency [4-6].

In 1980, for the first time in history, the MBBR system was used in Norway for wastewater treatment. These bioreactors have advantages such as low-pressure drop. Their resistance to factors such as temperature changes, pesticides, $\mathrm{pH}$ changes are also very good. Today, more than 500 MBBR systems are used to treat wastewaters and remove BOD, COD, nitrification, etc. all around the world [7,8]. It is also an optimal system for processes such as organic matters removal, nitrification, and denitrification since it has high efficiency in eliminating and reducing biodegradable organic and inorganic matters. Basically, the MBBR system is an evolved type of fixed bed and activated sludge system defined based on biofilms so that, the microorganisms can stick to polyethylene carriers and start the process of filtration. In aerobic processes, the movement of carriers is due to the aeration while in anaerobic reactors, using a mixer (with a horizontal or vertical shaft) helps carriers to move. MBBR system does not require secondary treatment. Additionally, the whole volume of the reactor can be used for microorganisms' growth [9]. Todays, MBBR systems are used in textile wastewater domestic wastewater, sewage, livestock, poultry, refineries, and petrochemicals [10], industrial wastewaters [11] and so on.

In 2006, Xiao et al. [12] conducted a test to present the structural features of biomass in the hybrid MBBR aeration tank [12]. The experiment took place in two subsequent periods, which differed in hydraulic and substrate loads. The physical characteristics of attached-growth biomass, such as biofilm thickness, density, porosity, and inner and surface fractal dimensions were studied. Moreover, parameters of suspendedgrowth biomass including floc size distribution, density, porosity, inner and surface fractal dimensions, were investigated and compared to those of attached-growth biofilms. The authors used the activated sludge, and MBBR systems with filling ratio of 70\% from Kaldnes carriers in two subsequent periods. The average density of attached-growth biofilm was 5 - 13 times higher than that of activated sludge flocs, though they were coexisting in the same reactor and same ecological environments. The boundary fractal dimension of biofilm was found to be always higher than that of activated sludge flocs.

In 2007, Choi and his colleagues [13] conducted a research on two different systems i.e., MBBR system and an integrated continuous bed activated sludge (ICBAS) system [13]. Researchers used these systems for nitrification and denitrification in both summer and winter seasons. The results showed that the MBBR system performs better than ICBAS in ambient air conditions in removing ammonia. In addition, the limited conditions for refining were not an obstacle for MBBR to have higher performance compared to that of ICBAS. Similar experiment was carried out by Motsch et al. [14] at Water Protection and Prevention Agency in Virginia-USA [14]. During the operation, favorable outcomes were obtained e.g., for the MBBR system the ammonia removal efficiency was higher than that of ICBAS. The tough environmental conditions for treatment process when using ICBAS, resulted in changes in the mixed liquor suspended solid (MLSS) level.

In 2010, Ferrai and colleagues [15] studied the kinetic and stoichiometric parameters by testing MBBR biofilms for urban wastewater treatment [15]. Authors used isolated and nonisolated samples from a large-scale laboratory MBBR, and oxygen uptake rate (OUR) heterotrophic sections of biomass for study. It was then modeled using ASM3 system. Isolated biofilms showed more tendency to sediment inside the bioreactor compared to non-isolated biofilms. Additionally, it was observed that there is a limited growth of biomass inside sediment sludge.

In other experimental research, Stamper and his colleagues studied the effects of combining MBBR system with an anaerobic system for better and stronger treatment [16]. Authors predicted that the anaerobic systems are prone to failure and require a lot of investment.

Also, in 2015, Mr. Barwal and his colleagues [17] investigate the effects of bio-carriers on the oxygen uptake rate in the effluent of the reactor with an aim to provide optimized filling ratio for the practical operation of a MBBR [17]. The value of OUR increased 2-3 times with the augmentation of carrier filling ratio, but it decreased when more carriers were added inside the reactor.

In 2015, Goswami et al. [18] compared ASP and MBBR systems performance in composting wastewater treatment plant made of chrome [18]. The plant contained desensitizable substances such as phosphorus, sulfur, chromium, and other toxic substances. Authors concluded that the higher the number of biofilms was, the higher the concentration of biomass was. 
Additionally, the results indicated that COD removal rate in MBBR was $80 \%$, which was much higher than that of ASP (60$70 \%)$. However, there was no difference in nitrogen removal for two reactors.

In 2016, Sayyah-Zadeh and colleagues [19] tried to improve the efficiency of the MBBR system in order to treat hydrocarbons using active carbon monoxide carriers [19]. Researchers monitored the performance of the system by filling the carrier's holes with activated carbon granules made of almonds and walnuts. Parameters i.e., activated carbon concentration (ACC), COD, and media filling ratio (MFR) were measured. The results showed that the removal efficiency of COD and total petroleum hydrocarbon (TPH) in the MBBR using carriers filled by almond and walnut is higher than that of polyethylene carriers.

In the same year, Young et al. [20] conducted research to study effects of low temperatures on the ammonia removal efficiency in a MBBR bioreactor [20]. The process was carried out between 1 and $20^{\circ} \mathrm{C}$. Various biofilms were observed inside the carriers in $20^{\circ} \mathrm{C}$ rather than $1^{\circ} \mathrm{C}$. Authors could thicken the biofilm thickness at $1^{\circ} \mathrm{C}$. Results indicated that under hard conditions (low temperature, chocks, and so on) the removal efficiency of ammonia gets lower mainly due to low mass transfer.

Recently, Haung and his colleagues [21] prepared a report on the importance of attached biomass in IFAS, MBBR and MBR systems [21]. The results showed that MBBR had better performance in naphthenic acids removal. Most recently, a study was done on the removal of organic solids from the wastewater using MBBR system. As an important result, it became clear that the MBBR system had the power to break down the drug substances [22-24].

The main objectives of this study, considering literature review, can be summarized as follow:

a) In previous studies, effects of a limited range of temperature on the amount of COD removal has been addressed. Studied rages are 1 to $20{ }^{\circ} \mathrm{C}$ and 30 to $50{ }^{\circ} \mathrm{C}$

\section{MBBR configuration and operation}

$[20,25]$. This means that there is not a comprehensive understanding about the temperature effect on the MBBR system behavior. In this experimental study to enhance the current knowledge, the removal efficiency of different amounts of COD and the activity of microorganisms on the lab-scale MBBR system where temperature ranges from 19 to $32{ }^{\circ} \mathrm{C}$ will be studied.

b) Literature review shows that the maximum studied COD in the wastewater stream was $2500 \mathrm{mg} / \mathrm{l}$. In current research, evaluation of the performance of a lab-scale MBBR system will be investigated using different input CODs up to $3500 \mathrm{mg} / \mathrm{l}$.

c) There is lack of comprehensive knowledge about the optimal HRT determination as well as its effects on BOD removal efficiency. Therefore, in this study, while determining the optimal HRT, its effects on the removal of BOD and COD will be addressed.

d) Despite the previous studies in which K1 and K2 carriers have been used, in this research, K3 carriers will be utilized in industrial wastewater treatment process.

\section{Materials and Methods}

Generally, in order to build the MBBR reactor, the following steps were considered. Moreover, necessary chemicals were prepared, and mandatory tests were carried out.

At first step, the lab-scale MBBR was designed and made to conduct the tests, which will be described in section 2.1. At second step, industrial wastewater sludge was prepared, and then specific volume of sludge was poured into the MBBR reactor. Consequently, artificial wastewater was added to the primary sludge. After that, the system was aerated. Subsequently, microorganisms were adapted to refine and remove organic matters. After ensuring that the sludge was compatible with artificial wastewater and COD was stable inside the bioreactor, COD and BOD removal rates were investigated at different HRTs and temperatures.

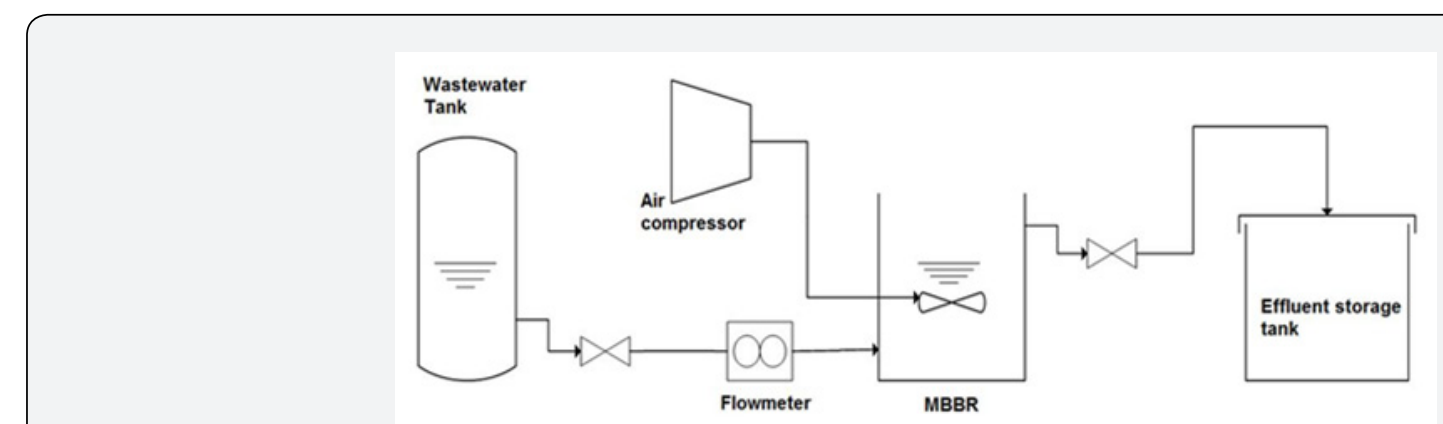

Figure 1: Schematic diagram of the studied MBBR system.

Figure 1 represents the schematic diagram, and Figure 2 shows the experimental setup of the MBBR system studied in this study.
The bioreactor is made of Plexiglas, which has a thickness of $6 \mathrm{~mm}$. The length of the bioreactor is $30 \mathrm{~cm}$, and its width is $15 \mathrm{~cm}$. It's pure and wastewater filled heights are 40 and $24 \mathrm{~cm}$, respectively. In order to control inlet and outlet of the fluids 
and to sample wastewater from the bioreactor, five valves were connected to the rectors as follow: one valve was connected to the bottom of the reactor and four valves connected to the bioreactor's walls with distances of $5,10,25$, and $35 \mathrm{~cm}$ from bottom of the bioreactor. To run the bioreactor, 12 liters of the bioreactor volume was filled with dense sludge (Return sludge of Pegah Co. East Azerbaijan). Then the total volume of the fluid inside the bioreactor was reached to the 24 liters by adding artificial wastewater. The experimental set-up of the MBBR system is shown in Figure 2.

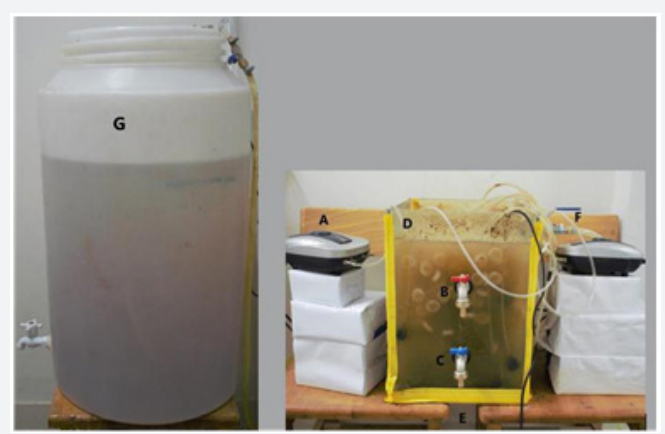

Figure 2: The MBBR system utilized in this research. (A): Aeration pump, (B): Sampling valve, (C): Extra

sludge discharge valve, (D): MBBR bioreactor, $(E)$ : Tank drain valve, $(F)$ : Outlet valve, $(\mathrm{G})$ : Artificial wastewater reservoir. Note that, the figure is combined from two different photos to show the exact scales.

Table 1: Characterization of the packing K3 Purchased from Pakzist Co.

\begin{tabular}{|c|c|c|c|c|c|c|}
\hline $\begin{array}{c}\text { Specific } \\
\text { Weight }\end{array}$ & $\begin{array}{c}\text { Specific } \\
\text { Surface }\end{array}$ & Density & $\begin{array}{c}\text { Mate- } \\
\text { rial }\end{array}$ & $\begin{array}{c}\text { Hei- } \\
\text { ght }\end{array}$ & $\begin{array}{c}\text { Overall } \\
\text { Dia- } \\
\text { meter }\end{array}$ & Color \\
\hline $\begin{array}{c}95 \mathrm{~kg} / \\
\mathrm{m}^{3}\end{array}$ & $\begin{array}{c}500 \mathrm{~m}^{2} / \\
\mathrm{m}^{3}\end{array}$ & $95 \mathrm{~kg} / \mathrm{m}^{3}$ & HDPE & $10 \mathrm{~mm}$ & $25 \mathrm{~mm}$ & White \\
\hline
\end{tabular}

From standard Kaldnes packing medias, the K3 carrier manufactured by Pakzist Co., was used to fill the bioreactor. Figure 3 shows the different types of Kaldness carriers including $\mathrm{K} 1, \mathrm{~K} 2$, and K3. The characteristics of the K3 packing media used in this study are presented in Table 1 . In order to suspend carriers inside the bioreactor and supply the required oxygen, three small air pumps with a total aeration rate of 8 liters per minute were used.

\section{Chemicals and measuring devices}

All the chemicals utilized in this study were purchased from Merck. The main chemicals used in this research are as follows:

a) $\mathrm{H}_{2} \mathrm{SO}_{4}, \mathrm{~K}_{2} \mathrm{Cr}_{2} \mathrm{O}_{7}, \mathrm{HgSO}_{4}$ and $\mathrm{Ag}_{2} \mathrm{SO}_{4}$ to measure COD,

b) Silica gel to balance solid's moisture and weight,

c) $\mathrm{K}_{2} \mathrm{HPO}_{4}$ and $\mathrm{KH}_{2} \mathrm{PO}_{4}$ salts as sources of phosphorus,

d) $\mathrm{CH}_{4} \mathrm{~N}_{2} \mathrm{O}$ as nitrogen sources to provide a ratio of $\mathrm{P}: \mathrm{N}$ : COD of 1: 5: 100 [26], e) Molasses as a source of nutrition feed for biofilms and COD stabilization.

The following devices were also used to perform measurements and tests:

a) Spectrophotometer (UV-VIS 2800 manufactured by Unico) for COD measurement,

b) Digital scale (AS 220 R2 model manufactured by Rad Wag) with a precision of 0.001gram, BOD measurement device (OXITOP RESPIROMETER),

c) Avon (YCO-500-64 model manufactured by Yaran) for measuring MLSS

d) Air pumps (Air-8000 made by Resun Company, and AT703 manufactured by Atman) to supply demanded oxygen.

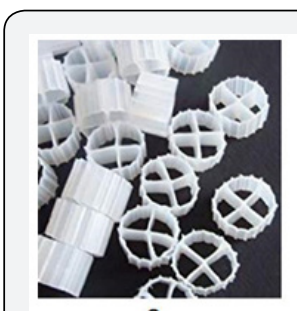

a

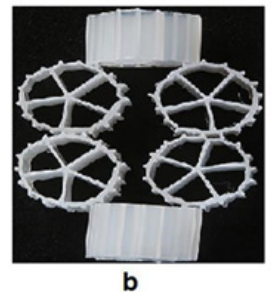

b

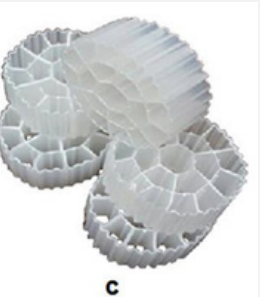

Figure 3: Different types of Kaldness carriers: (a): K1, (b): K2, and (c): K3.

\section{Preparation of the artificial wastewater}

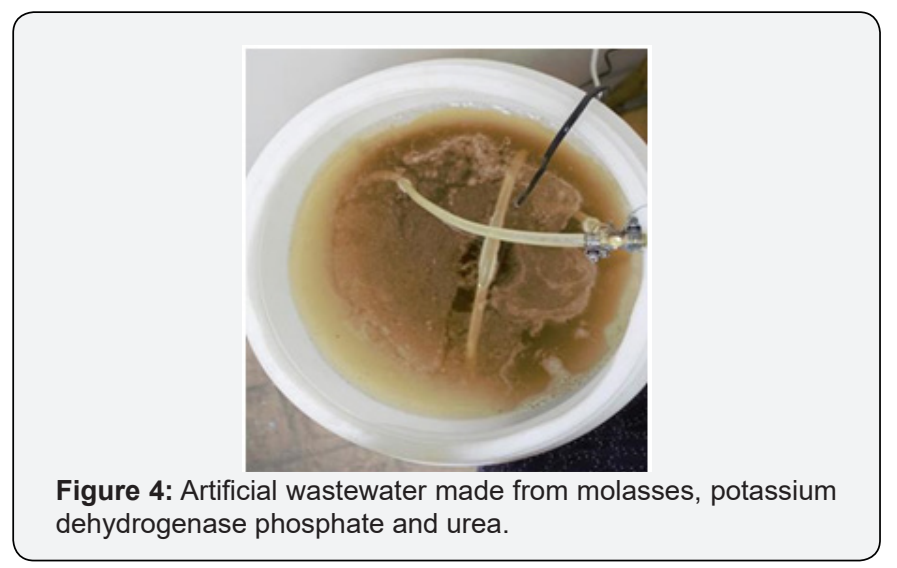

Molasses, potassium dehydrogenase phosphate and urea were utilized to make artificial wastewater. Molasses were used to stabilize the COD of the sewage entering the bioreactor and to fix the COD of the initial wastewater contained within the bioreactor. Also, $\mathrm{K}_{2} \mathrm{HPO}_{4}$ was used to stabilize phosphorus level in the initial wastewater contained within the bioreactor. In addition, urea $\left(\mathrm{CH}_{4} \mathrm{~N}_{2} \mathrm{O}\right)$ was used to stabilize nitrogen level in the initial wastewater inside the bioreactor.

\section{Adaptation of sludge and microorganisms}

At first step, to adapt the slurry environment for the activity of microorganisms, synthetic wastewater as feed was injected into the MBBR system daily. Meanwhile the system was 
continuously aerated to stabilize the MLSS of the wastewater in the bioreactor. After one month of commissioning the system, the MLSS and COD parameters were sampled from the bioreactor for the measurement purpose. During the period of adaptation of the sludge and microorganisms, the temperature of the laboratory was between 16 and $17^{\circ} \mathrm{C}$. After 90 days, the system's MLSS was stabilized at $3200 \mathrm{mg} / \mathrm{l}$. Moreover, the COD removal rate was about $45 \%$, indicating the adaptation of the sludge and microorganisms [26]. Finally, the $\mathrm{pH}$ of the system was adjusted to about 7 , which is very suitable for growth of the microorganisms [26]. It should be noted that at the end of the adaptation period, the very first biofilm layers were observed on the internal surfaces of the K3 carriers. At the same time the external surfaces of the carriers became slippery.

\section{Sampling for analysis}

Following procedure was used to sample and analyze. First, after a specific period, the aeration pump was turned off to allow the sludge to be deposited inside the bioreactor. Then, for the COD test, $500 \mathrm{ml}$ of wastewater sampled from the bioreactor. According to the results of the COD removal, a certain amount of the same sample selected for BOD measurement. Due to the aerobic nature of the process of microorganism activity inside the system, supply of oxygen for microorganisms is very important. Therefore, by performing regular tests $\mathrm{pH}$ control parameters and MLSS were evaluated. When MBBR was running, the $\mathrm{pH}$ of the system was kept at an average of 7, and the MLSS was maintained at a range of $3500-3000 \mathrm{mg} / \mathrm{l}$ [26].

\section{Results and Discussion}

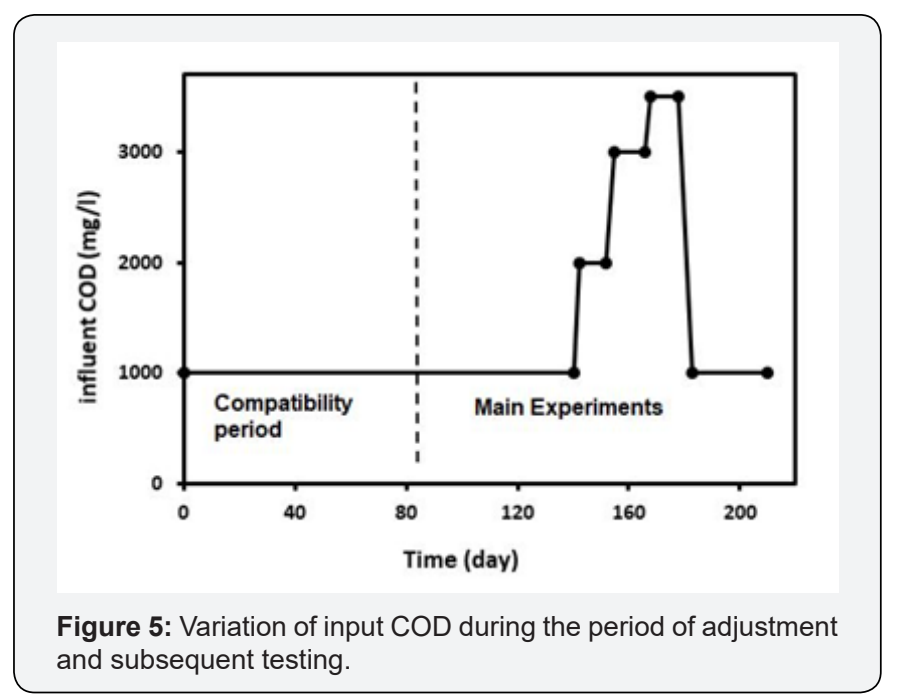

Upon completion of the adaptation period (90 days), the main experiments were carried out. During the tests, the following objectives were studied:

a) Effects of influent wastewater with High COD on MBBR system performance,

b) Effects of HRT on bioreactor operation (removal of BOD and COD) in order to find an optimum HRT, c) Effects of bioreactor temperature on its performance while using input wastewater with average COD of 1000 $\mathrm{mg} / \mathrm{l}$ in optimal HRT.

Variation of inlet wastewater COD with time during the microorganism's adaptation and main experiments has been presented in Figure 5.

\section{Biofilm growth}
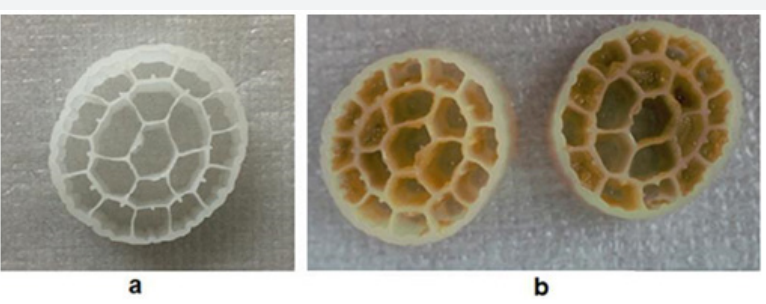

Figure 6: (a) Before formation of biofilm, and (b) after formation of biofilm.

As already mentioned, at the end of the MBBR system compatibility period, biofilm formation was observed on the surface of the carriers and the external surfaces of the carriers got slippery [5]. After approximately one week (since the end of the adaptation period) the number of biofilms increased significantly. Figure 6 shows the inner and outer surfaces of K3 carrier before and after the formation of the biofilm layers. It should be noted that on the outer surfaces of some media packings, only a very thin layer of biofilm is observed. This is due to aeration and collision of the carriers which causes that the biofilm sticking to the outer surface of them is peeled and become a suspended biomass. For this reason, the inner surface of the media packings is considered an effective surface for biofilm formation.

\section{HRT effect analysis}

The removal efficiency of COD and BOD at different HRTs for the constant loading of $\mathrm{COD}=1000 \mathrm{mg} / \mathrm{l}$ was investigated to find the optimum HRT. It worth mentioning that in previous studies, the MBBR system functionality evaluated at low HRTs, had a maximum COD removal at HRT of 2 hours [4].

Figure 7 shows the amount of effluent COD and BOD at a constant loading rate of $\mathrm{COD}=1000 \mathrm{mg} / \mathrm{l}$ and $\mathrm{BOD}=490 \mathrm{mg} / \mathrm{l}$ at different HRTs. As shown in both Figure 7a \& 7b, the COD and BOD effluent at HRT of 12 hours is the lowest which means both COD and BOD removals are the highest. In addition, the efficiency of both BOD and COD removals have been compared at different HRTs in Figure 8. As known, the amount of COD removal is always higher than BOD removal as COD represents both organic and non-biodegradable organic compounds, but BOD only contains biodegradable organic compounds. Also Figure 8 indicates that at low HRTs, COD is more eliminated in comparison with BOD. The reason is the lack of required time to start the activity of microorganisms in order to remove organic matter with biological treatments. 


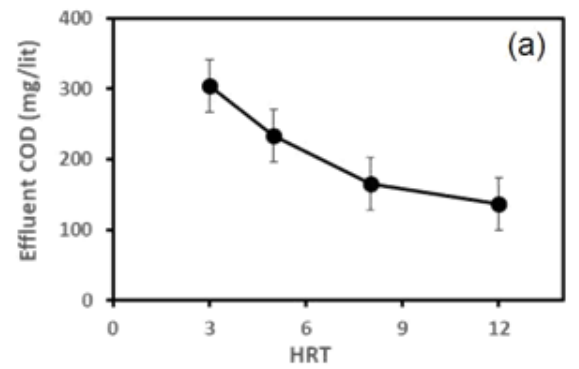

Figure 7: Variation of outlet COD (a) and BOD

By increasing HRT, enough time to start the activity of these microorganisms is provided. On the other hand, as shown in Figure 8, the removal efficiency of COD and BOD at HRT of $12 \mathrm{~h}$ is more than the others, which is $87 \%$ and $75 \%$, respectively. At HRT of 8 hours, these efficiencies were calculated $84 \%$ and $71 \%$, respectively. As the biological treatment processes are time consuming, and there is a marginal difference between removal efficiencies at HRT of 8 and 12 hour, someone may choose HRT = $8 \mathrm{~h}$ as an optimal HRT.

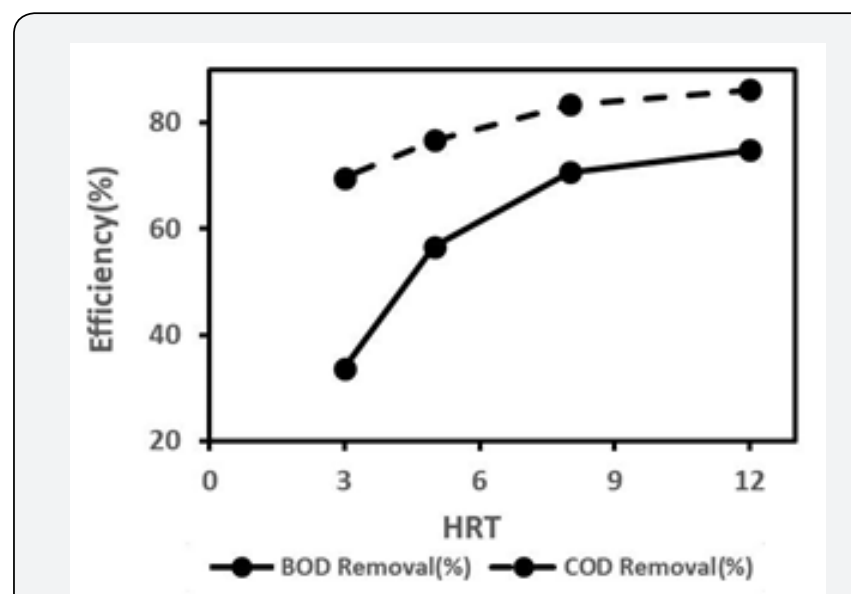

Figure 8: Variation of $\mathrm{BOD}$ and $\mathrm{COD}$ removal efficiencies at different HRTs with filling ratio of $50 \%$.

\section{Effects of different input CODs in optimal HRT analysis}

Since industrial wastewater has high CODs, treatment process should be done by a system which saves both time and cost. In the Figure 9, effects of inlet COD up to $3500 \mathrm{mg} / \mathrm{l}$ on the MBBR system performance (COD removal efficiencies) has been shown. It should be considered that the COD of the system was continuously increased from 1000 to $3500 \mathrm{mg} / \mathrm{l}$. As the results indicate, the COD removal follows a non-monotonic behavior along with increasing the amount of inlet wastewater COD. This can be understood considering behavior of the microorganisms. At inlet COD range between 1000 to $2000 \mathrm{mg} / \mathrm{l}$, microorganisms still have the capacity to absorb more organic compounds. Therefore, with increasing COD up to $2000 \mathrm{mg} / \mathrm{l}$, the removal efficiency also increases. However, beyond COD 2000mg/l microorganism's capacity for further COD removal is full. Therefore, an increase in inlet COD amount up to $\sim 3000 \mathrm{mg} / \mathrm{l}$

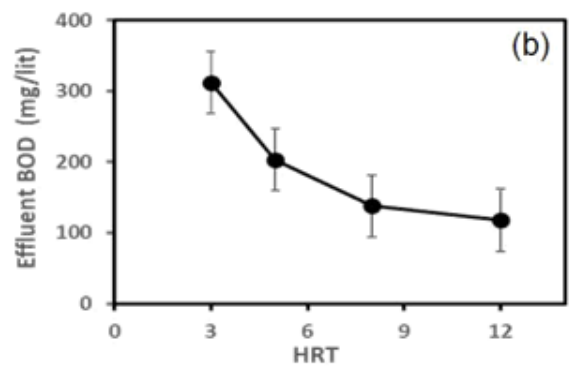

(b) at different HRTs with a filling ratio of $50 \%$.

results in accumulation of COD inside bioreactor. Thus, this ends in reduction of COD removal efficiency. However, when resident time increases the MBBR system gets compatible with high CODs $(\sim 3000 \mathrm{mg} / \mathrm{l})$. Subsequently, this leads to an increment in both activity and number of microorganisms. Consequently, these result in COD removal increase. As Figure 9 also shows, the MBBR system has higher efficiencies $>80 \%$ at high CODs, which can indicate that the MBBR system is suitable for industrial wastewater treatment processes.

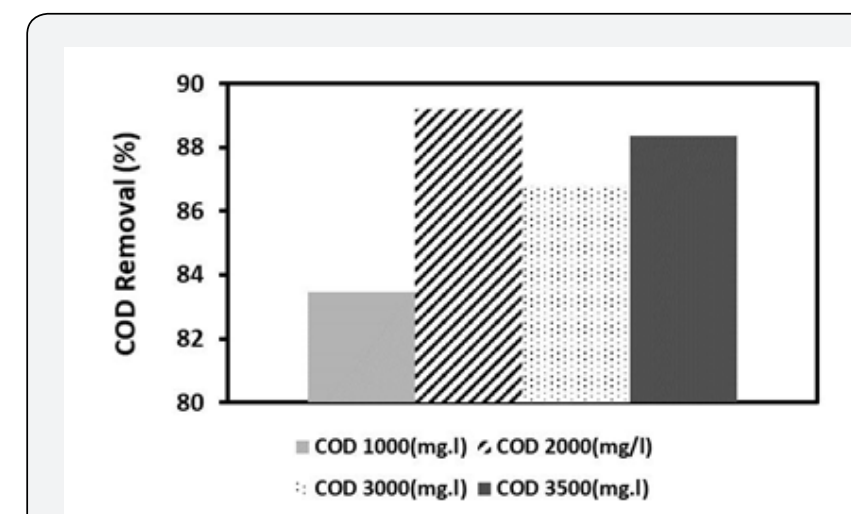

Figure 9: Variation of $\mathrm{COD}$ removal with different wastewater inlet COD when filling ratio is $50 \%$.

\section{Temperature effect analysis}

As already mentioned, temperature is one of the most important parameters in biofilm growth rate and compatibility during system stabilization for testing [27]. Due to the lack of sufficient knowledge about the effects of temperature on the performance of the MBBR system, and in order to enhance current knowledge, the system performance was studied at a temperature range of 19 to $32^{\circ} \mathrm{C}$. Effects of temperature variation on the COD removal efficiency has been shown in Figure 10. According to the results, the COD removal efficiency diagram can be divided into three phases. As shown in phase (a), the COD removal efficiency is increases very slowly to $\sim 72 \%$ between 19 to $21^{\circ} \mathrm{C}$. In phase (b), there is an abrupt increase in the removal efficiency reaching up to $90 \%$. In phase (c), the removal efficiency is increased slightly.

Overall, this behavior of removal efficiency can be rationalized as follow: In phase (a) (approximately less than $20^{\circ} \mathrm{C}$ ) due to the 
limited ability of microorganism's adaption with low temperature conditions; the COD removal efficiency increases very slowly up to $\sim 72 \%$. By increasing the temperature of the system from $20^{\circ} \mathrm{C}$ up to about $25^{\circ} \mathrm{C}$ (phase b), due to the sudden rise in the microorganism's activity, sharp increase in COD removal efficiency from $\sim 72 \%$ to $\sim 92 \%$ happens. At the same time, the thickness of biofilms also increases. The highest COD removal efficiency of $94 \%$ occurs at a temperature of $32^{\circ} \mathrm{C}$ in phase (c), which is much better than the results reported in literature [25]. However, from 25 to 32 , as mentioned, the removal efficiency rate increases slowly. For example, the COD removal efficiency is $92 \%$ at $27^{\circ} \mathrm{C}$. The biofilm thickness observed in inner surfaces of the carriers at $32^{\circ} \mathrm{C}$ is higher than the biofilm thickness at $27^{\circ} \mathrm{C}$. In general, increasing the thickness of the biofilm reduces the mass transfer and decreases the rate of increment in removal efficiency. Hence, it is expected that due to the reduction in mass transfer, the COD removal efficiency will grow very slowly by increasing temperature from 25 to above $32^{\circ} \mathrm{C}$.

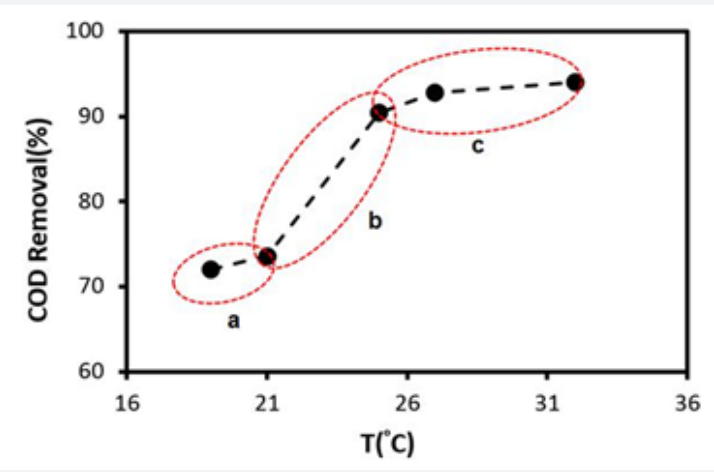

Figure 10: Variation of COD removal efficiency at different temperatures with filling ratio of $50 \%$.

\section{Conclusion}

MBBR is one of the modern and innovative systems for urban and industrial wastewater treatment. Many studies have been done to prove that this system is suitable for wastewater treatment process in comparison with others. MBBR does not have common problems such as sludge bulking and rising, foaming, poor sludge settling, and carriers clogging. Some features such as strong resistance to impact, and no need to return the sludge make the system much easier to operate [4]. Besides, it is tenacious at high temperatures and CODs, as well as against shocks such as $\mathrm{pH}$ [28] etc.

In this study, after adaptation of microorganisms and their accumulation on K3 carriers, system performance was studied by examining the removal efficiency of BOD and COD at different HRTs, temperature, and wastewater inlet CODs. Studied COD range was 1000 to $3500 \mathrm{mg} / \mathrm{l}$. It was for first time that K3 carriers were used to study the MBBR system.

The BOD and COD parameters were determined at HRTs of 3, 5,8 , and 12 hours with a filling ratio of $50 \%$. Although the HRT of 12 hours had a COD removal efficiency of $86 \%$, but because of a slight difference of $3 \%$ and shortening the treatment process, HRT of 8 hours was selected as an optimum HRT.

In addition to choosing the optimal HRT, the effects of different temperatures ranging from 19 to $32^{\circ} \mathrm{C}$ were also investigated. The results indicate that there is an abrupt change in the COD removal efficiency at temperature range between 20 to $25^{\circ} \mathrm{C}$ because of high activity of the microorganisms. By raising the temperature to $25^{\circ} \mathrm{C}$, the activity of microorganisms is relatively reduced, and the rate of COD removal efficiency increment is decreased. According to the results, the optimum operating temperature was suggested to be $27^{\circ} \mathrm{C}$

In MBBR systems, high level of inlet wastewater COD is also an essential and important factor in system's performance detection, since in industrial and urban wastewaters the number of organic compounds is high. Therefore, the effects of different inlet CODs up to $3500 \mathrm{mg} / \mathrm{l}$ were studied. The results indicate a non-monotonic behavior of the MBBR system, which can be understood considering the behavior of microorganisms in different CODs. In general, for all COD values, the MBBR system always has a removal efficiency more than $80 \%$.

\section{References}

1. Ishak S, Malakahmad A, Isa MH (2012) Refinery wastewater biological treatment: A short review. Journal of Scientific and Industrial Research 71(4): 251-256.

2. Ji M, Yu J, Chen H, Yue LP (2001) Removal of slowly biodegradable COD in combined thermophilic UASB and MBBR systems. Environ Technol 22(9): 1069-1079.

3. Cao CY, Zhao YH (2012) The Comparison of MBBR and ASP for Treatment on Petrochemical Wastewater. Journal of Petroleum Science and Technology 30(14): 1461-1467.

4. Javid AH, Hassani AH, Ghanbari B, Yaghmaeian K (2013) Feasibility of utilizing moving bed biofilm reactor to upgrade and retrofit municipal wastewater treatment plants. International Journal of Environmental Research 7(4): 963-972.

5. Biswas K, Taylor MW, Turner SJ (2013) Successional development of biofilms in moving bed biofilm reactor (MBBR) systems treating municipal wastewater. Appl Microbiol Biotechnol 98(3): 1429-1440.

6. Mangesh G, Ashwini I (2015) Moving Bed Biofilm Reactor: A Best Option for Wastewater Treatment. International Journal for Scientific Research \& Development 3(1): 1094-1096.

7. Amit K, Troy H, Vikram P (2008) MBBR pilot study for Tertiary nitrification of HPOAS wastewater at Harrisburg AWTF. The Water Environment Federation's Technical Exhibition and Conference.

8. Christian C, Eoin S, Ray CA, Chandler J (2009) Lessons learned on longterm operation of MBBR for refinery wastewater treatment. The Water Environment Federation's Technical Exhibition and Conference.

9. Sudol MZ (2012) Moving bed technology as an alternative solution for reducing bioreactor volume. Journal of Environment Protection Engineering, 38(3): 16-22.

10. Diya'uddeen BH, Daud WMAW, Aziz ARA (2011) Treatment technologies for petroleum refinery effluents: A review. Journal of Process Safety and Environmental Protection 89(2): 95-105.

11. Bering S, Mazur J, Tarnowski K, Janus M, Mozia S, et al. (2018) The application of moving bed bio-reactor (MBBR) in commercial laundry wastewater treatment. Sci Total Environ 627: 1638-1643. 
12. Xiao GY, Ganczarczyk J (2006) Structural features of biomass in a hybrid MBBR reactor. Environ Technol 27(3): 289-298.

13. Nancy C, Heather P, Terry LJ, Ralph B, Thomas L (2007) Pilot testing of MBBR and IFAS treatment processes for nitrification and denitrification at the mamaroneck WWTP. The Water Environment Federation's Technical Exhibition and Conference.

14. Sarah M, Dan F, George G, John M, Tom W (2007) MBBR and IFAS pilot program for denitrification at fairfax county's noman cole pollution control plant. The Water Environment Federation's Technical Exhibition and Conference, 2007.

15. Ferrai M, Guglielmi G, Andreottola G (2010) Modelling respirometric tests for the assessment of kinetic and stoichiometric parameters on MBBR biofilm for municipal wastewater treatment. Department of Civil and Environmental engineering. Journal of Environmental of Modelling and Software 25: 626-632.

16. Gali S, Tamar A, Nir A, Antoine E, Alje H, et al. (2011) Integrated anaerobic-aerobic MBBR: a novel approach to high strength wastewater treatment. The Water Environment Federation's Technical Exhibition and Conference, 2011.

17. Anjali B, Rubina C (2015) Impact of carrier filling ratio on oxygen uptake \& transfer rate, volumetric oxygen transfer coefficient and energy saving potential in a lab-scale MBBR. Journal of Water Process Engineering 8: 202-208.

18. Supriyo G, Debabrata M (2015) Comparative study between activated sludge process (ASP) and moving bed bioreactor (MBBR) for treating composite chrome tannery wastewater. International Conference on Advances in Bioprocess Engineering and Technology 2016 (ICABET 2016) 3(10 Part A): 3337-3342.

19. Sayyahzadeh AH, Ganjidoust H, Ayati B (2016) MBBR system performance improvement for petroleum hydrocarbon removal using modified media with activated carbon. Water Sci Technol 73(9): 2275-2283.
20. Young B, Delatolla R, Kennedy K, Laflamme E, Stintzi A (2017) Low temperature MBBR nitrification: Microbiome analysis. Water Res 111: 224-233.

21. Huang C, Shi Y, Xue J, Zhang Y, El-Din MG, Liu Y (2016) Comparison of biomass from integrated fixed-film activated sludge (IFAS), moving bed biofilm reactor (MBBR) and membrane bioreactor (MBR) treating recalcitrant organics: importance of attached biomass. Journal of Hazardous Materials 326: 120-129.

22. Casas ME, Chhetri RK, Ooi G, Hansen KM, Litty K, et al. (2015) Biodegradation of pharmaceuticals in hospital wastewater by staged Moving Bed Biofilm Reactors (MBBR). Water Res 83: 293-302.

23. El-Taliawy H1, Casas ME, Bester K (2018) Removal of ozonation products of pharmaceuticals in laboratory Moving Bed Biofilm Reactors (MBBRs). J Hazard Mater 347: 288-298.

24. Tang K, Ooi GTH, Litty K, Sundmark K, Kaarsholm KMS, et al. (2017) Removal of pharmaceuticals in conventionally treated wastewater by a polishing Moving Bed Biofilm Reactor (MBBR) with intermittent feeding. Bioresour Technol 236: 77-86.

25. di Biase A, Devlin TR, Kowalski MS, Oleszkiewicz JA (2017) Performance and design considerations for an anaerobic moving bed biofilm reactor treating brewery wastewater: Impact of surface area loading rate and temperature. J Environ Manage 216: 392-398.

26. Metcalf and Eddy, Wastewater Engineering, ( $4^{\text {th }}$ edn).

27. Zhou H, Li X, Xu G, Yu H (2018) Overview of strategies for enhanced treatment of municipal/domestic wastewater at low temperature. Sci Total Environ 643: 225-237.

28. Zhou H, Wang G, Wu M, Xu W, Zhang X, et al. (2018) Phenol removal performance and microbial community shift during $\mathrm{pH}$ shock in a moving bed biofilm reactor (MBBR). J Hazard Mater 351: 71-79.

This work is licensed under Creative Commons Attribution 4.0 License DOI: 10.19080/IJESNR.2019.20.556031

\section{Your next submission with Juniper Publishers will reach you the below assets}

- Quality Editorial service

- Swift Peer Review

- Reprints availability

- E-prints Service

- Manuscript Podcast for convenient understanding

- Global attainment for your research

- Manuscript accessibility in different formats ( Pdf, E-pub, Full Text, Audio)

- Unceasing customer service

Track the below URL for one-step submission https://juniperpublishers.com/online-submission.php 